\title{
Sobre el milenarismo de Joaquín de Fiore. Una lectura retrospectiva
}

Debo manifestar públicamente, ante todo, mi agradecimiento a la Pontificia Universidad Católica de Chile, por la invitación que me ha cursado, y muy particularmente a su Facultad de Teología y su Instituto de Historia. Es un gran honor para un investigador europeo acudir a esta casa de estudios, que remonta a 1888 , y que ha mantenido ininterrumpidamente su actividad desde entonces, lo cual la convierte -con la Universidad de Chile, que, por sus estatutos de 1879, recuperó su labor docente- en una de las más antiguas universidades de América Latina, excepción hecha, naturalmente, de la Universidad de San Marcos en Lima, que, con altibajos, remonta a 1551. Evidentemente, también va mi reconocimiento más sentido a la Universidad Alberto Hurtado y a la Universidad Nacional Andrés Bello, copatrocinadoras de este "Seminario internacional sobre milenarismo, mesianismo, pensamiento utópico y escatología".

\section{PRELIMINARES}

Joaquín de Fiore (ca. 1130-1202) vivió una de las épocas más interesantes del medievo. Participó en la segunda Cruzada y tuvo en Constantinopla una intensa experiencia mística que reorientó su existencia. En esa vivencia espiritual intuyó tanto su método "exegético concordístico" como su particular forma de entender la ciencia teológica. Conoció los años de Enrique II Plantagenet y Leonor de Aquitana y los cuatro hijos de estos (¿quién no recuerda a Ricardo Corazón de León y Juan sin Tierra?). Tuvo noticia directa de la tumultuosa vida de Federico I Barbarroja, emperador del Sacro Imperio. Ya al límite de sus días, siguió desde su retiro calabrés el desarrollo de la tercera Cruzada. Presenció el despegue del mundo urbano y de las escuelas catedralicias y el repliegue de las escuelas monásticas. Quizá le llegaron ecos del arranque titubeante del gótico, de las primeras summae teológicas y de la creación de la universidad parisina. Incluso es probable que se inquietara por las campañas almohades en Hispania. Contemporáneo de Averroes y de Maimónides, asistió a los orígenes del ciclo artúrico y de los grandes poemas épicos naciona- 
les, como el Cantar del Mío Cid, y contempló el declive del feudalismo, en su momento de máximo esplendor.

Protagonista de excepción del tránsito del alto al pleno medievo, pensador de una originalidad y un vigor excepcionales, ha sido, quizá por ello mismo, una de las figuras más manipuladas de la historia del pensamiento occidental.

Por mi parte, no renuncio a tal manipulación. No es, pues, mi propósito criticar tal instrumentalización, como quizá hayan ustedes imaginado. Por el contrario, me propongo continuarla e, incluso, ampliarla. Con todo, intentaré dilucidar en qué ha sido extorsionada su figura y por qué, y estableceré algunas hipótesis de trabajo, que desearía discutir con ustedes en el coloquio, si realmente logro suscitar el interés de mi auditorio.

Han sido muy variadas las aproximaciones historiográficas al corpus joaquinita. Es obvio que cada época ha tenido sus intereses particulares al arrimarse al poliédrico sistema joaquinita. Esta noche me voy a centrar especialmente en el supuesto o real milenarismo del Abad calabrés. Pero no puedo pasar por alto su doctrina trinitaria.

Obviamente no puedo orillarla, so pena de devaluar por completo de nervio especulativo su sistema teológico. Además, su trinitología, debidamente ensamblada en una peculiar teología de la historia, constituye uno de los capítulos más interesantes y vigorosos de la teología monástica, hasta el punto de haber traspasado las fronteras del medievo, desembarcando en la Ilustración y el Romanticismo.

\section{LA POLÉMICA DE JOAQUÍN DE FIORE CON PEDRO LOMBARDO}

Quedan ya muy lejos, evidentemente, las discusiones conciliares de 1215 sobre la doctrina trinitaria del Abad Joaquín. El debate sobre su ortodoxia se halla muy bien resumido en la segunda decretal del Lateranense IV, titulada Damnamus ergo, y fue comentada con gran acierto por Tomás de Aquino, poco después de 1260. Joaquín polemizó acerca del núcleo mismo del misterio trinitario y, por ello, su discusión con el lombardo ha sido ampliamente recogida por la manualística.

Por resumir brevemente aquel debate, de gran calado teológico (1), habría que aclarar, ante todo, que se enfrentaban dos concepciones teológicas distintas, por no decir contrapuestas: la griega y la latina. El Abad Joaquín rechazaba, en su De unitate seu essentia Trinitatis, la formulación teológica de Pedro Lombardo. Acusaba de cuaternarista al Maestro de las Sentencias, por enseñar que en Dios hay tres Personas y una esencia. Entendía que tres Personas y una esencia son cuatro "cosas", es decir, cuatro res (2). Joaquín, que se había convertido en Constantinopla, cuando tomaba parte en la segunda Cruzada, y que habitaba en el sur de Italia, tan fuertemente influido por el ambiente bizantino, no podía aceptar la posición lombardiana. Sin embargo, el Concilio Lateranense dio la razón a Pedro Lombardo. ¿Qué

(1) Cfr., por ejemplo, Elisabeth REINHARDT, Contenidos teológicos del "Damnamus ergo". Santo Tomás vs. Joaquín de Fiore, en "Florensia”, 13/14 (1999-2000) 339-350, con bibliografía; e íd., Joaquín de Fiore y el IV Concilio Lateranense, en “Anuario de Historia de la Iglesia”, 11 (2002) 95-104.

(2) La autoría joaquinita del De unitate Trinitatis, opúsculo que no se ha conservado, ya no se discute. 
había ocurrido? Pues que el florense no había entendido los tecnicismos del Maestro de las Sentencias.

La reacción del florense tiene fácil explicación, al menos desde mi punto de vista. Su sincera y sentida devoción a la Santísima Trinidad, cultivada en los ambientes bizantinos, y después plasmada en su teología de la historia, chocaba con los tecnicismos lombardianos. Otro factor, además, esta vez típicamente latino-occidental, le impedía aceptar los planteamientos del Maestro de las Sentencias. Voy a intentar exponerlo en pocas palabras, invitándoles a retrotraer su mirada al contexto filosófico de la segunda mitad del siglo XII.

En aquel marco tan contaminado de hiperrealismo, en el que las esencias universales se tomaban como subsistentes incorpóreos puestos en las cosas sensibles, cada uno de los supuestos existentes solo podía ser: o un accidente de una esencia subsistente, o él mismo una esencia subsistente. En el caso de la Trinidad, no podía pensarse que las Personas divinas fuesen accidentes o manifestaciones de la esencia divina, porque se incurriría en el modalismo. Quedaba solo una salida al dilema: que cada Persona divina fuese ella misma su esencia. Estamos de acuerdo en la conclusión, aunque no en el razonamiento. Pero sigamos.

En un horizonte hiperrealista, decimos, en el que las esencias eran subsistentes en las cosas, establecer que el misterio trinitario consiste en confesar la trinidad de personas en la unidad de la esencia, equivalía a introducir cuaternidad en Dios. Cada persona debía ser su esencia; y, además, la esencia misma tenía que ser subsistente aparte. Por consiguiente, las Personas divinas solo podían constituir una unidad moral o un colectivo. He aquí la crítica del florense (cfr. DH 803).

Pedro Lombardo había formulado la fe trinitaria correctamente; sin embargo, el florense, que también confesaba la Santísima Trinidad, no pudo entender la formulación lombardina, por defecto de su herramienta filosófica. Ahora, superado ya el clima hiperrealista altomedieval, la discusión planteada por Joaquín de Fiore contra Pedro Lombardo ha perdido mucho interés, aun cuando el tema fuera entonces importantísimo y continúe siéndolo, como cualquier teólogo dogmático reconocería de inmediato.

La pregunta, que quizá ustedes se hayan formulado, es: ¿qué queda de Joaquín de Fiore a los ochocientos años de su fallecimiento, si aquella discusión trinitológica ha sido sepultada en el olvido por obsoleta? Y la respuesta podría ser: conservan toda su actualidad las cavilaciones joaquinitas sobre el milenio (o los dos milenios) (3), profetizados en el capítulo 20 del Apocalipsis (Apoc 20, 1-8). No obstante, contra lo

(3) "Vi un ángel que bajaba del cielo, con la llave del abismo y una gran cadena en la mano. Apresé al dragón, la serpiente antigua, que es el diablo y Satanás, y lo encadenó por mil años. Lo arrojó al abismo, lo cerró y puso un sello en él, para que no seduzca más a las naciones hasta que pasen los mil años. Después debe ser soltado por poco tiempo. Vi también unos tronos; a los que se sentaron en ellos se les dio potestad de juzgar; y vi las almas de los degollados por dar testimonio de Jesús y de la palabra de Dios, y vi a los que no adoraron la bestia ni su imagen ni recibieron la marca en su frente ni en su mano. Revivieron y reinaron con Cristo mil años. Los demás muertos no revivieron hasta que se cumplieron los mil años. Esta [aquella] es la resurrección primera. Bienaventurado y santo el que tiene parte en la resurrección primera. Sobre estos la muerte segunda no tiene poder, sino que serán sacerdotes de Dios y de Cristo, y reinarán con Él mil años. Cuando se hayan cumplido los mil años, Satanás será soltado de su prisión, y saldrá a seducir a las naciones que hay en los cuatro ángulos de la tierra, a Gog y Magog, y a reunirlos para la guerra, siendo innumerables como la arena del mar" (Apoc 20, 1-8). 
que afirman tantos manuales, el florense nunca se manifestó premilenarista (4). Esta es la paradoja de la historiografía. ¿Fue quizá postmilenarista? ¿Amilenarista acaso? Tendremos ocasión de tratarlo (5).

\section{PRECISIONES TERMINOLÓGICAS}

Antes de continuar con la exposición es necesario ofrecer algunas precisiones terminológicas. Como ya hemos insinuado, conviene distinguir tres tipos de milenarismos. El amilenarismo, el premilenarismo y el postmilenarismo (6).

Los tres milenarismos tienen a la vista el famoso capítulo 20 de Apocalipsis, en el que se habla de dos milenios: uno, en el que Satanás está atado; y otro, en el que Cristo reina con los "degollados", es decir, con los mártires (¿y con los confesores?) que ya han revivido. Se habla allí también de dos muertes: una muerte de los que ya no van a morir más, y una segunda muerte, en la que pueden incurrir todos menos los mártires. También se alude a dos resurrecciones: la resurrección de los degollados que han revivido y reinan con Cristo por mil años, y una segunda resurrección, cuando se haya cumplido el milenio en que Satanás ha estado atado.

Veamos ahora con más detalle los tres tipos de milenarismos. Se entiende por amilenarismo la doctrina que sostiene que Satanás fue maniatado en el momento en que Cristo murió en la Cruz, de modo que ya ha sido derrotado, aun cuando conserve -por permisión divina- un cierto poder sobre los hombres, hasta que sea definitivamente precipitado en los infiernos, en la segunda venida de Cristo. Ese reinado terreno de Cristo coincide con la historia de la Iglesia viadora o Ecclesia in terris. Tal es la posición católica desde que san Agustín, a finales del siglo IV, disipó por completo las dudas premilenaristas de los Padres prenicenos. Los muertos, pues, resucitarán en la segunda venida de Cristo, comparecerán en el Juicio universal y recibirán entonces su destino eterno (premio o castigo).

Por premilenarismo se entiende, en cambio, la doctrina que confiesa que Cristo vendrá para reinar durante mil años, durante el transcurso histórico, al cabo de los cuales tendrá lugar la definitiva venida de Cristo con toda majestad, se cerrará la historia y se establecerá el reino definitivo. Durante ese milenio intrahistórico, Cristo reinará en la tierra con sus ángeles y con los que ya entonces habrán resucitado en esa venida intermedia, previa a la definitiva o parusía, antes, por tanto, de la resurrección final del resto de los mortales. Hay tres tipos de premilenarismo, que tienen en común el afirmar que la humanidad pasará por un breve período de gran contra-

(4) Josep Ignasi SARANYANA, Sobre el "milenarismo" de Joaquín de Fiore en su interpretación del Apocalipsis, en "Florensia", 13/14 (1999-2000) 351-363.

(5) Una posición muy próxima al autor que suscribe este ensayo puede verse en: Kurt-Victor SELGE, Trinität, Millenium, Apokalipse im Denken Joachims von Fiore, en Roberto RUSCONI (ed.), Gioacchino da Fiore tra Bernardo di Clarvaux e Innocenzo III, Viella, Roma 2001, pp. 49-69. Potestà sostiene un hipotético milenarismo, aunque muy sui generis, de Joaquín: Gian Luca POTESTÀ, Linee di ricerca e questioni aperte riguardo a Gioacchino da Fiore e la sua eredità storica e dottrinale, en "Anuario de Historia de la Iglesia", 11 (2002) 105-110.

(6) Un desarrollo más amplio, al discutir la escatología evangélica contemporánea, en Josep Ignasi SARANYANA, La Escatología en España (y $I V)$, en "Anuario de Historia de la Iglesia”, 10 (2001) 325-352, aquí p. 328. 
dicción antes de la parusía. Los hay que sostienen que la Iglesia será arrebatada y presentada a Cristo antes de esa gran persecución (pretribulacionistas); otros que afirman que será arrebata durante la tribulación (mediotribulacionistas), y otros que sostienen que será arrebata al fin de la gran prueba (postribulacionistas).

Se puede hablar finalmente de postmilenarismo, posición que hoy pocos comparten. Fue, sin embargo, muy común en el siglo de las Luces, y se esconde detrás de la fe en el progreso indefinido de la humanidad. Se afirmaba, entonces, que, durante un milenio, la progresiva maduración de los dones evangélicos debía preparar la segunda venida de Cristo; una felicidad cada más perfecta e irreversible, al cabo del cual tendría lugar la parusía.

\section{LOS DOS COMENTARIOS DE JOAQUÍN AL APOCALIPSIS}

Joaquín de Fiore comenzó, hacia 1181-1183 (7), cuando se retiró a la abadía de Casamavi, dos comentarios al Apocalipsis, que no estarían terminados hasta 1199. Su meditación sobre el Apocalipsis fue, pues, un trabajo lento y muy laborioso, al que dedicó casi un tercio de su vida. Ambos comentarios (uno corto y otro largo) fueron editados conjuntamente por las Juntas de Venecia, en 1527, con el título único de Expositio in Apocalypsim (8), figurando el comentario corto como introducción al comentario más extenso. En esa edición veneciana, el corto se titula: Praephatio sive liber introductorius in expositionem Apocalipsis [sic]. El segundo: In expositione Apocalipsis [sic]. Kurt-Victor Selge ha reconstruido la historia de estas dos obras y ha mostrado la complejidad de su proceso redaccional (9). En cualquier caso, y esto es lo importante, en ellas se nos muestra en todo su esplendor la novitas ioachimita (10).

(7) Sobre su vida y doctrina cfr., entre otros: Josep-Ignasi SARANYANA, Joaquín de Fiore y Tomás de Aquino. Historia doctrinal de una polémica, EUNSA, Pamplona 1979.

(8) JOACHIM VON FIORE, Expositio in Apocalypsim, Venedig 1527, reprint Minerva, Frankfurt a. M. 1964.

(9) Joaquín de Fiore habría comenzado su Expositio in Apocalypsum en Casamari hacia 1183, terminándola definitivamente en 1198/99. Un primer esbozo de su Praephatio dataría de 1188-90 (edición crítica de Kurt-Victor Selge); un esbozo del Liber introductorius, desechado y finalmente transformado, como libro independiente, en el Enchiridion super Apocalypsim, dataría de 1195 (edición crítica bastante satisfactoria de Edward Kilian Burger); un Liber introductorius definitivo, compuesto en veintiséis capítulos, dataría de 1197/98/99. Cfr. Kurt-Victor SELGE, L'origine delle opere di Gioacchino da Fiore, en Ovidio CAPITANI y Jürgen MIETHKE (eds.), L'attesa della fine dei tempi nel Medioevo, Società editrice il Mulino ("Annali dell'Istituto storico italo-germanico in Trento", Quaderno 28), Bolonia 1990, pp. 87-131. Una descripción general de los comentarios de Joaquín de Fiore al Apocalipsis, en: Bernard McGINN, L'abate calabrese. Gioacchino da Fiore nella storia del pensiero occidentale, trad. ital., Marietti, Roma 1990, pp. 159-174 (V. "Prendi il libro e divoralo: Gioaechino e l'Apocalisse").

(10) Recientemente se han publicado varias ediciones críticas del Enchiridion o comentario breve, que tuvo dos etapas previas, desechadas, que la crítica conoce, respectivamente, con el nombre de Praephatio y Liber introductorius. JOACHIM OF FIORE, Enchiridion super Apocalypsim, ed. Edward Kilian Burger, Pontifical Institut of Mediaeval Studies, Toronto 1986 (edición crítica); GIOACCHINO DA FIORE, Sull'apocalipse, traduzione e cura di Andrea Tagliapietra, Paoline, Milano 1994 (texto bilingüe latín-italiano, con bibliografía); GIOACCHINO DA FIORE, Introduzione all'apocalisse, cura del Centro Internazionale di Studi Gioacchimiti ("Opere di Gioacchino da Fiore. Testi e Studi”, 6), presentación de Kurt-Victor Selge, trad. de Gian Luca Potestà, Editore Viella, Roma 1995 (texto bilingüe latino-italiano). 
Como era de esperar, el cotejo de los índices de los dos opúsculos apocalípticos, redactados casi contemporáneamente, revela que no hay, entre ellos, diferencias importantes en cuanto al contenido. Todo lo que se halla en el Liber introductorius se encuentra también en la Expositio; en otros términos, solo varía la extensión que se concede a los temas: son más largos los desarrollos de la Expositio que los del Introductorius.

Así las cosas, una lectura de las dos obras revela que el Abad florense constituye un caso paradigmático de manipulación historiográfica; una "fascinante figura", como lo ha calificado la medievalística, en torno a la cual han cristalizado expectativas quilialistas de distinto signo. Henri de Lubac lo ha comprobado en un libro que quizá haya irritado a los puristas de la investigación, pero que ha acertado de pleno al trazar la trayectoria de su "posteridad doctrinal" (11). En mi opinión, hay un auténtico gap entre el Joaquín de la historia y el joaquinismo, de forma que Joaquín se ha convertido en un imaginario en el que se han proyectado muchas de las aspiraciones de la humanidad a lo largo de los siglos. En todo caso, aunque ese imaginario haya podido falsear la genuina doctrina del Abad florense, incluso haya mistificado sus más íntimas convicciones religiosas y teológicas, es preciso reconocer que Joaquín ha podido dar pie para ese proceso histórico de recreación. Al hilo del corpus joaquinita, el subconsciente colectivo se ha lucido de veras. El Liber introductorius in evangelium aeternum, preparado por Gerardo de Borgo San Donnino, de 1254, constituye el primer hito importante de tal manipulación; y la consiguiente reacción de los maestros seculares parisinos, la segunda prueba. Después vendrían las polémicas sobre la pobreza franciscana, las Conformidades de la vida de San Francisco a la del Señor Jesús, de Bartolomé de Pisa (finales del siglo XIV), los opúsculos de Cristóbal Colón (principios del siglo XVI) (12), y un largo etcétera que llega a nuestros días, con la novela de Umberto Eco, titulada El nombre de la rosa...

Los textos de Joaquín hablan por sí mismos y desmienten las posteriores relecturas. Pero es inútil nadar contracorriente: los libros tienen su propia vida, cuando son puestos en circulación, con derroteros que asombrarían a sus autores, si pudieran protestar. En tal sentido, se puede decir que Joaquín de Fiore es un clásico que pide a gritos que llegue cuanto antes a buen puerto la edición crítica de sus escritos, apenas comenzada (13).

En este punto, precisamente, en la lectura (sesgada o no) de Joaquín de Fiore, presentándolo como premilenarista, se produce la confluencia entre el tema de mi exposición y el argumento principal de este simposio organizado en homenaje a Manuel Lacunza, en el segundo centenario de su muerte, acaecida en Imola (Italia), en 1801 .

(11) Cfr. Henri DE LUBAC, La posterité spirituelle de Joachim de Flore, P. Lethielleux, Paris 1979-1981, 2 vols.

(12) Cfr., por ejemplo, Roberto RUSCONI, Profezia e profeti alle fine del Medioevo, Viella, Roma 1999, pp. 229-259 ("Il Libro de las profecías di Cristoforo Colombo. Retroterra culturale e consapevolezza di uno scopritore").

(13) Cfr. Kurt-Victor SELGE, La edición crítica de las "Opera omnia" de Joaquín de Fiore, en "Anuario de Historia de la Iglesia", 11 (2002) 89-94. 


\section{JOAQUÍN DE FIORE Y EL "JOAQUINISMO"}

Una cuestión hermenéutica clásica, en efecto, desde que fue formulada por el tardorromanticismo alemán, es la distinción entre un personaje histórico y su recepción por el "espíritu del pueblo". Quizá haya sido Friedrich Daniel Ernst Schleiermacher (1768-1834) uno de los primeros en llamar la atención sobre este difícil tema. Las conclusiones de Schleiermacher son altamente problemáticas para un cristiano, porque postulan expresamente la distinción entre Jesús y Cristo. Los dogmas cristianos y las instituciones no serían otra cosa que expresiones históricas puntuales a través de las cuales evolucionaría y se desarrollaría el sentimiento. Cristo estaría, obviamente, en el centro de la experiencia cristiana, pero su existencia histórica concreta se difuminaría para mantener solo su función.

Según David Friedrich Strauss (1808-1874), muy influido por Schleiermacher, la tradición crearía mitos, particularmente en materias religiosas (14). En otros términos: los hechos bíblicos se habrían transformado poco a poco en dogmas, por vía de evolución. En consecuencia, los mitos serían creaciones inconscientes de la comunidad, concepciones del espíritu colectivo, alumbramientos del alma del pueblo. Aparquemos ahora la cuestión cristológica, que directamente implicó a los románticos alemanes, sobre todo al citado Strauss, en el debate sobre la historicidad de los evangelios (15), e intentemos un rastreo en busca de los orígenes del joaquinismo a partir del genuino pensamiento de Joaquín de Fiore (16).

Para un lector del siglo XXI, la definición de mito, asumida tal como la proponían los románticos alemanes, resulta un tanto anacrónica. No así, en cambio, cuando el término mito se toma alegóricamente. Entonces el mito se convierte en un relato que tiene dos aspectos, ambos igualmente necesarios: lo ficticio y lo real. Lo ficticio -comenta Ferrater Mora- consiste en que, de hecho, no ha ocurrido lo que dice el relato mítico. Lo real estriba en que, de algún modo, lo que dice el relato mítico responde a la realidad (17). El mito creado por el pueblo pretende dar razón de algo que realmente ha ocurrido y que no es posible expresar con claridad y nitidez por medio de un discurso formalizado. Las palabras rodean el misterio, dicen (o pueden decir) algo verdadero del misterio, pero no lo agotan. Juan Pablo II ha empleado en este sentido el término mito, aplicado al segundo relato de la creación

(14) Cfr. sobre la evolución de Strauss, desde que conoció a Schleiermacher, en 1831, hasta su muerte, en 1874: Miguel Ángel TABET, David F. Strauss: "La vida de Jesús", Emesa ("Crítica Filosófica", 11), Madrid 1977.

(15) La brecha entre el Jesús histórico y el Cristo de la fe es insostenible, porque Jesús se presentó a sí mismo como el Cristo de la fe (cfr., por ejemplo, entre los muchos pasajes, Mt. 16, 18). Además, existe una continuidad esencial entre el kérigma de Jesús, el de los Apóstoles y el de la primitiva Iglesia. Cfr. PABLO VI, Exhortación apostólica Evangelii nuntiandi, de 8.12.1975; y JUAN PABLO II, Encíclica Redemptoris missio, de 7.12.1990.

(16) Me he ocupado con más amplitud de este tema, en polémica con el Prof. Jaime R. Lara, de la Universidad de Yale, en un trabajo titulado: Joaquín de Fiore y el joaquinismo, publicado en Ana de ZABALLA BEASCOECHEA (ed.), Utopía, mesianismo y milenarismo. Experiencias latinoamericanas, Universidad San Martín de Porres (Escuela Profesional de Turismo y Hostelería), Lima 2002, pp. 57-71,

(17) José FERRATER MORA. Diccionario de Filosofía, Ariel, Barcelona 1994, III, ad vocem (edición revisada, aumentada y actualizada por Josep-Maria Terricabras). 
del hombre (Gén 2,18) y al lenguaje simbólico bajo el que se expresa la caída original (Gén. 3) (18).

Supuesto todo cuanto hemos dicho, nuestra hipótesis es que se ha producido una disociación entre la verdadera doctrina del Abad florense y la recepción que de ella ha hecho un sector radicalizado de la fraternidad franciscana (los "espirituales" o "fraticelos"). En definitiva, el profeta Joaquín ha sido mitificado y su mitificación ha dado lugar al joaquinismo. Hay en el joaquinismo algo del verdadero Joaquín; pero también hay ficción en él, precisamente lo que proyecta sobre Joaquín el inconsciente colectivo,

La génesis del joaquinismo se habría desatado, según nuestra opinión, al poco de fallecer san Francisco, y habría tenido un primer momento crítico a finales de la década de los cincuenta (1257), cuando san Buenaventura fue elegido maestro general de la Orden. Un segundo momento álgido habría que situarlo a comienzos del siglo XIV, poco después del Concilio de Vienne, coincidiendo con las condenas de Juan XXII relativas a la interpretación exagerada de la pobreza (1318) por parte de los fraticelos. La fuga de Guillermo de Ockham y Miguel de Cesena, de Avignon a Munich (1328), coinciden con la caída del telón. La posterior polémica entre los imperialistas y regalistas con los papalistas, y las sucesivas oleadas de peste bubónica, cambiaron por completo de escenario y de representación.

A lo largo de esos ciento cincuenta años se habría generado, a partir del corpus joaquinita, la corriente que se conoce con el nombre de joaquinismo. El protagonismo de Guillermo de Borgo de San Donnino, "inventor" del Joaquín autor del Evangelio eterno (1254) es indiscutible, aunque no único. En los orígenes del joaquinismo gravitaría, a nuestro entender, una mitificación del carisma profético del Abad florense (tan bellamente cantado por Dante Alighieri en su Divina comedia), especialmente una recreación de sus profecías acerca de los dos testigos del Apocalipsis, de las que hablaremos con detenimiento más adelante.

En ese florense mitificado, recibido por los fraticelos y después por otros grupos, habría a la vez, por tanto, verdadera doctrina joaquinita y recreación de la comunidad. Veamos un ejemplo. Se puede conjeturar que la doctrina de los tres estados, tan característica del opus joaquinita, se inscribe contextualmente en una defensa de los movimientos "laicales", aparecidos a finales del siglo XII. Gian Luca Potestà lo ha subrayado con perspicacia: "Esta división [estado del Padre, estado del Hijo, estado del Espíritu Santo] respondía a un imperativo de 'teología social': la potente armadura ternaria permitía rehabilitar la antigua doctrina de las tres ordines, exaltando el ordo monástico, presentado como protagonista del tercer estado, y, al mismo tiempo, ofrecía un espacio claro, aunque limitado, a la acción de los laicos. [...] Así, pues, Joaquín rechazaba tanto la dura persecución contra los cátaros y valdenses, como la crítica contra los ambientes parisinos que justificaban la predicación de los laicos" (19). Es discutible, con todo, si tal fue la verdadera intención de Joaquín, porque en su comentario largo al capítulo 9 del Apocalipsis desacredita y

(18) Cfr. JUAN PABLO II, Audiencia general, de 7.11.79. Vid. También íd., Carta apostólica Mulieris dignitatem, de 15.8.88, n. 9.

(19) Véase Gian Luca POTESTÀ, Linee di ricerca e questioni aperte riguardo a Gioacchino da Fiore e lla sua eredità storica e dottrinale, cit. en nota 5, p. 107. 
critica duramente a los patarinos, movimiento laico surgido en el norte de Italia, a finales del siglo XI, que dio origen a predicadores laicos ambulantes, que tronaban contra el clero corrupto (20). Cualquiera que haya sido la intención del florense (condenar a los valdenses al tiempo que anatematizaba a los patarinos), los fraticelos tomaron las aseveraciones de Joaquín como arma arrojadiza contra los franciscanos conventuales. Las profecías sobre el tercer estado, sin signos ni figuras, en el que prevalecerían los monjes laicos por encima del sacerdocio, desarrolladas por el florense al hilo del Apocalipsis, habrían dado pie a todo tipo de elucubraciones y fantasías. Así pues, de una auténtica devoción trinitaria y de una proyección social de esa devoción, se habría pasado a una instrumentalización de la doctrina de los tres estados, para justificar una determinada comprensión del franciscanismo.

En el Apocalipsis leemos, en efecto, que dos testigos vestidos de saco profetizarán durante mil doscientos sesenta días (21), al cabo de los cuales la bestia los matará, para resucitar tres días y medio después (Apoc 11, 1-5). La tradición exegética medieval había señalado que los dos testigos prefiguraban a Elías y Moisés, que se habían aparecido en el Monte Tabor, junto a Cristo, en la Transfiguración. Otro había dicho que Elías y Enoc serían moralmente como un único personaje, uno de los dos testigos, mientras que el otro sería Moisés. Junto a estas dos interpretaciones, de las que se hace eco el florense, el Abad señala una tercera (22): que los dos personajes podían también prefigurar algunos hombres espiritua-

(20) Este movimiento surgido en la Pataria, que tuvo como epicentro Milán, presentaba algunos rasgos comunes con los cátaros discípulos de Pedro Valdo o valdenses de Lyon, más tardíos, contemporáneos de Joaquín de Fiore, y con los albigenses, también de esos mismos años. Pero, evidentemente, no fueron lo mismo. Su concepción extrema e incorrecta de la pobreza que debía exigirse a los clérigos, a quienes los patarinos acusaban de no observar la vida apostólica, es decir, la vida de la primitiva Iglesia; su dualismo también radical, condenando cualquier matrimonio lícito, las también muy tajantes prohibiciones sobre alimentos; y su negación de la encarnación del Hijo de Dios, "dicentes omnem carnem creatam a Dyabolo [fuisse]", eran inaceptables y fueron censuradas por la Iglesia. El Abad Joaquín también los condenó, como signo del anticristo, poniendo a los patarinos (quienes, no obstante, "arbitrabuntur se obsequium praestare Deo") en el mismo saco que los sarracenos y los turcos, y que las prefiguraciones individuales del anticristo, entre quienes contó a Mahoma y al emperador Federico I. Véase Expositio in Apocalypsim [comentario largo], III pars, in cap. 9, §§ 1, 3, 11, 13 (ed. de 1527, pp. 130vb, 131ra-b, 132vb-133ra, 133va-135va). Las mismas ideas se repiten en su otra obra contemporánea De articulis fidei y en la ligeramente posterior Tractatus super quattuor Evangelia. Cfr. sobre este tema: Giovanni GONNET, Gioachino da Fiore e gli eretici del suo tempo, en Storia e messaggio in Gioacchino da Fiore. Atti del I Congresso Internazionale di Studi Gioachimiti, Centro di Studi Gioachimiti, S. Giovanni in Fiore 1980, pp. 57-69.

(21) San Juan tiene a la vista la profecía de Daniel y la explicación del Arcángel San Gabriel (Dan 9, 20-27), habían sido fijadas setenta semanas (de años) para acabar con las transgresiones y expiar el pecado de la Ciudad Santa, distribuidas de la siguiente manera: siete semanas previas a la restauración de la ciudad y aparición del ungido, sesenta y dos semanas de restauración efectiva hasta la muerte del ungido, una semana en que desaparecerá el pacto entre Dios y el pueblo, a la mitad de la cual se instalará la abominación en el templo, durante media semana. Tres años y medio de abominación son cuarenta y dos meses. Si cada mes tiene treinta días, cuarenta y dos meses son mil doscientos sesenta días (1.260). Tomando los días por años, el año 1260 fue señalado como el año supuestamente joaquinita, determinado por los joaquinistas como el año en el que se cumpliría la profecía de los dos testigos vestidos de saco.

(22) Expositio in Apocalypsim, Venedig 1527, reimpresión de Minerva Verlag, Frankfurt 1964, ff. 147rb-147va. Corresponde, pues, al comentario más extenso, de los dos que escribió el Abad Florense. 
les (aliqui spirituales viri) o dos órdenes de justos (duo ordines iustorum) designados por ellos (23).

Joaquín consideró que identificar los dos profetas con dos varones espirituales, que darían origen a dos órdenes de justos, no era contraria a la fe, aunque no constituía su opinión preferida. Él se adhirió más bien a la tercera opinión, según la cual los dos testigos representan a tres varones: Enoc, Elías y Moisés. Enoc significaría la era de los patriarcas, o sea, el tiempo del Padre; Moisés, la era de la Ley, prefigurando la edad del Hijo; y en Elías se daría la similitud de la vida eremítica (porque se le creía fundador de los eremitas del Monte Carmelo), que se asemeja al Espíritu Santo.

En cambio, la atribución al florense de la primera interpretación (dos varones que fundan dos órdenes), como su tesis más propia y característica, fue obra muy posterior del franciscanismo, que hallamos ya plenamente formulada en las Conformidades de Bartolomé de Pisa, a fines del siglo XIV. Con ello se justificaba una forma peculiar de entender el franciscanismo.

He aquí, pues, cómo se crea una doctrina a partir de un texto y se atribuye a un autor, que no la mantuvo directamente ut talis (aunque pudo dar pie a esa atribución). Obviamente, mi explicación constituye solo un ejemplo. Con todo, ilustra cómo a partir del corpus joaquinita pudo desarrollarse el joaquinismo.

\section{EL “JOAQUINISMO” Y EL IMAGINARIO MILENARISTA}

Ya hemos señalado que no está suficientemente fundada la opinión que adscribe al florense al premilenarismo. Hay que, preguntarse si no habría que contarlo entre los postmilenaristas, como ya hemos apuntado al comienzo de nuestra lección. Obviamente, no a un postmilenarismo grosero y burdo; pero ¿acaso a un postmilenarismo mitigado? ¿Podemos pensar que en el opus de Joaquín haya elementos que podrían haberse desarrollado postmilenarísticamente?

Nuestra opinión es que, entendida la novitas ioachimita un tanto superficialmente, el tercer estado, sin signos ni figuras, apropiado al Espíritu Santo, pudo dar pie a una interpretación postmilenarista. Joaquín profetizó, en efecto, que en el tercer estado surgiría una especie de orden eremítica de carácter laical (por así decir). ¡Qué fácil era tomar ese tercer estado como una preparación de la segunda venida del Mesías en gloria y majestad!

No obstante, y en descargo del florense, conviene subrayar que él nunca separó el segundo estado del tercero, que se solaparían (según sus predicciones), de la misma forma que la sexta y séptima etapa de la historia corren paralelas, según la teología agustiniana (24). Pero a la muerte del Abad florense, sus tesis evolucionaron autónomamente, dando lugar a una interpretación que habría sorprendido a su creador. ¿De qué forma? Esto ocurrió concretamente en los años de la Ilustración y del Romanticismo.

(23) Qui designantur per illos. Es discutible el antecedente de illos. Podría ser apostolos, patriarchas, spirituales viros. En mi opinión, el antecedente de per illos son los dos testigos.

(24) Cfr., por ejemplo, una exposición amplia en Josep Ignasi SARANYANA, Tomás de Aquino y Joaquín de Fiore. Historia doctrinal de una polémica, EUNSA, Pamplona 1979, passim. 
No es el caso, ciertamente, de Manuel Lacunza, quien se apuntó al premilenarismo mitigado. Sus afirmaciones son obviamente inequívocas: "Después de la venida del Señor en gloria y majestad, habrá todavía un grande espacio de tiempo, esto es mil años, o indeterminados, o determinados, hasta la resurrección y el juicio final" (25). En cambio, sí fue el caso de Friedrich Wilhelm Joseph Schelling, que cita expresamente al florense en su Philosophie der Offenbarung (La Filosofía de la Revelación), su curso muniqués 1831-1832 (26). Aunque sus referencias parecen de segunda mano, son inequívocas, pero se insertan en un marco doctrinal ajeno a las pretensiones del genuino Joaquín (27).

Concluyo ya. Es preciso reconocer, con el historicismo, la tremenda fuerza creadora del espíritu humano, su gran capacidad de releer las doctrinas en contextos diferentes. Pero es necesario resistir críticamente a estos reclamos de la modernidad. Por consiguiente, distingamos entre Joaquín y el joaquinismo, y no caigamos en la fácil tentación de manipular a nuestro capricho las figuras más señeras de antaño, aunque la instrumentalización del pasado sea una de las técnicas retóricas más agradecidas.

\section{RESUMEN}

El artículo analiza la obra de Joaquín de Fiore y sostiene que hay un auténtico gap entre el Joaquín de la historia y el joaquinismo, de forma que Joaquín se ha convertido en un imaginario en el que se han proyectado muchas de las aspiraciones de la humanidad a lo largo de los siglos. Añade que en todo caso es preciso reconocer que el florense ha podido dar pie para ese proceso histórico de recreación. La hipótesis que se plantea es que se ha producido una disociación entre la verdadera doctrina del Abad florense y la recepción que de ella ha hecho un sector radicalizado de la fraternidad franciscana (los 'espirituales' o 'fraticelos'). La mitificación del profeta Joaquín ha dado lugar al joaquinismo. En definitiva, no está suficientemente fundada la opinión que adscribe al florense al premilenarismo, esto es, a la tesis que sostiene que Cristo vendrá para reinar mil años, en un transcurso histórico previo a la resurrección final de todos los muertos. Finalmente, es posible que la tesis de Joaquín sobre el tercer estado, sin signos ni figuras, haya permitido, según los términos utilizados en este artículo, una

(25) La venida del Mesías en gloria y magestad, ed. preparada por P. Chamrobert, Librería de Parmantier, París 1825. I, p. 174. Cfr. Josep Ignasi SARANYANA, El milenarismo lacunciano y la teología de la liberación, en "Anuario de Historia de la Iglesia”, 11 (2002) 141-149, aquí p. 143. La Iglesia había tolerado este premilenarismo mitigado, con tal de que no incurriese en exageraciones groseras y extremas. La primera censura importante fue redactada precisamente a petición del arzobispo de Santiago de Chile, don José María Caro Rodríguez. El decreto lleva fecha de 20 de julio de 1944, y puede leerse en DH 3839. Ya había sido comunicado al arzobispo de Chile, en carta de 11 de julio de 1941. A pesar de todo, esa condena es bastante suave en su formulación; se limita a señalar que el milenarismo mitigado "no puede enseñarse con seguridad [tuto doceri non posse]".

(26) Henri DE LUBAC, La posterité spirituelle de Joachim de Flore, cit., I. De Joachim à Schelling, pp. 386-387.

(27) En cambio, y contra lo que se ha dicho tantas veces, no hallamos en Hegel referencias explícitas, sino solo ideas que podrían, en el mejor de los casos, remitir a un joaquinismo sui generis. En Hegel, en efecto, lo que suena a joaquinismo más bien podría reconducirse a una especie de gnosticismo e incluso a la teosofía..., al menos según la interpretación de Henri de Lubac, con quien concuerdo plenamente. 
interpretación postmilenarista, esto es, la idea de un milenio de progresiva maduración de los dones evangélicos y de felicidad cada vez más perfecta e irreversible, al cabo del cual tendría lugar la parusía.

\begin{abstract}
This article analyses the work by Joachim de Fiore, claiming that there is a gap between the historical Joachim and the real Joachinism, which has turned him into an imaginary figure, in whom most of the humanity's ambitions have been reflected for years. The author argues that de Fiore might have given good reasons for this historical process of recreation. The hypothesis here put forward, is that a dissociation has occurred between the true doctrine of the Abbot de Fiore and its reception form a radical sector of the Franciscan fraternity (the spirituals or 'fraticeleos'). His mithification has given rise to Joachinism. However, there are no grounds for the claims that attribute pre-mileniarism to him, which states that Christ will come back to reign for a thousand years before the resurrection of the dead. In fact, it is likely that Joachim's thesis on the third stage, with no signs nor figures, may have accepted a post-milleniarist interpretation; i.e. the idea of a millennium of progressive maturation of the evangelical gifts and of a greater joy, more and more perfect and irreversible, after which the Final Things might come.
\end{abstract}

